\title{
Screening of candidate tumor-suppressor genes in 3p21.3 and investigation of the methylation of gene promoters in oral squamous cell carcinoma
}

\author{
KAI WANG ${ }^{1}$, TIANYOU LING ${ }^{1}$, HANJIANG WU ${ }^{1}$ and JIE ZHANG $^{2}$ \\ Departments of ${ }^{1}$ Stomatology, and ${ }^{2}$ Ophthalmology, Second Xiangya Hospital, \\ Central South University, Changsha, Hunan 410011, P.R. China
}

Received August 30, 2012; Accepted November 9, 2012

DOI: $10.3892 /$ or.2012.2213

\begin{abstract}
Oral squamous cell carcinoma (OSCC) is the most common type of head and neck malignant tumor. However, its pathological mechanisms have not yet been elucidated. In the present study, we screened for candidate tumor-suppressor genes (TSGs) related to OSCC among 10 candidate genes located in 3p21.3, a region abundant with TSGs based on previous studies, using semi-quantitative reverse transcription PCR (RT-PCR). Three genes, GNAT1, SEMA3B and AXUD1, with low or no expression in OSCC tissues and the cell line TCA8113 were selected, and the promotermethylation status was furtheranalyzed by methylation-specific PCR (MS-PCR). Hypermethylation in the promoter regions of $S E M A 3 B$ was found in OSCC tissues, and a significant difference in the frequency of methylation of SEMA3B was observed between OSCC and non-cancerous tissues. Furthermore, TCA8113 cells treated with 5-Aza-Cdc started to re-express $S E M A 3 B$ at a concentration of $5 \mu \mathrm{M}$ or higher. Our study confirmed that three candidate TSGs with low expression may be involved in OSCC and that hypermethylation in promoter regions may contribute to the low expression of $S E M A 3 B$. These findings offer novel insights for clarifying the molecular mechanisms of tumorigenesis of OSCC as well as for aiding in its clinical diagnosis and therapeutic strategy.
\end{abstract}

\section{Introduction}

Head and neck tumors are the common malignant tumors worldwide, while oral squamous cell carcinoma (OSCC) is the

Correspondence to: Dr Jie Zhang, Department of Ophthalmology, Second Xiangya Hospital, Central South University, 139 Middle Renmin Road, Changsha, Hunan 410011, P.R. China

E-mail: zhangjie740410@yahoo.com.cn

Dr Hanjiang Wu, Department of Stomatology, Second Xiangya Hospital, Central South University, 139 Middle Renmin Road, Changsha, Hunan 410011, P.R. China

E-mail:whj58@fc18.com

Key words: oral squamous cell carcinoma, 3p21.3, gene expression, gene promoter, hypermethylation most prevalent type of head and neck tumor accounting for $2-3 \%$ of malignant tumors and $80 \%$ of oral and maxillofacial malignant tumors $(1,2)$. Although the techniques of surgical treatment, radiotherapy and chemotherapy for OSCC have progressed in the past few decades, the 5-year survival rate of OSCC patients has shown no noticeable improvement $(3,4)$. Thus, it is crucial to explore the pathological mechanisms of OSCC, and new biomarkers must be identified and used in the detection of precancerous lesions, early diagnosis and therapy of OSCC.

Numerous factors, such as genetic alterations, epigenetic changes and environmental influence, are involved in the development of OSCC. Inactivation and deletion of tumor-suppressor genes (TSGs) play important roles in the development of carcinomas (5). Previous studies have suggested that analyzing the LOH (loss of heterozygosity) in tumor tissues can facilitate the identification of relevant TSGs. For example, $R B$ (6), p53 (7), Wilms tumor (WT) (8), cyclin-dependent kinase number 2 (CDKN2) (9), adenomatous polyposis coli $(A P C)(10)$, deleted in pancreatic carcinoma locus 4 (DPC4) (11), fragile histidine triad (FHIT) (12) and putative protein tyrosine phosphatase gene $(P T E N)(13,14)$ have all been identified using $\mathrm{LOH}$ analysis. As for OSCC, a high frequency of LOH has been observed on chromosomes $3 p$, $4 q, 5 q, 7 q, 8 p, 9 p, 11 q, 13 q, 18 q, 20 q, 21 q$ and $22 q$ regions using comparative genomic hybridization and LOH analysis (15-18). Thus, these chromosome segments appear to be target regions where TSGs of OSCC may exist.

Roz et al (19) found LOH at one or more loci of chromosome 3 p by investigating 30 oral dysplastic lesions, presenting clinically as either erythroplakias or leukoplakias with histopathological features of either severe epithelial dysplasia or carcinoma in situ. Furthermore, three discontinuous deletion regions including $-3 \mathrm{p} 13-21.1,-3 \mathrm{p} 21.3-5$ and $-3 \mathrm{p} 25$, were detected in patients with precancerous lesions and OSCC, which suggest that alterations of these three regions may be early events in the development of OSCC. Yamamoto et al (20) found different degrees of LOH at 3p21.3 in OSCC patients from Japan and India. At the same time, LOH at 3p21-22 was present in other common malignant tumors such as renal carcinoma (21), lung cancer (22), squamous cell carcinoma of the head and neck (23), cervical carcinoma (24) and 
Table I. Clinicopathological features of the oral squamous cell carcinoma patients.

\begin{tabular}{lccccccc}
\hline & & \multicolumn{2}{c}{ Gender } & & & \multicolumn{2}{c}{ Lymph node status } \\
\cline { 3 - 4 } Tumor subsite & Cases & Male & Female & Age (years) & Median age (years) & Positive & Negative \\
\hline Tongue & 28 & 24 & 4 & $17-80$ & 42.1 & 13 & 15 \\
Gum & 3 & 2 & 1 & $40-61$ & 50.3 & 1 & 2 \\
Soft plate & 1 & 1 & 0 & 73 & 53.0 & 0 & 1 \\
Floor of the mouth & 2 & 2 & 0 & 53 & 53.0 & 1 & 0 \\
Jaw bones & 2 & 1 & 1 & $48-59$ & & 2 & 0 \\
\hline
\end{tabular}

breast cancer (25). Several groups have studied the relevant TSGs for nasopharyngeal carcinoma (NPC) and lung cancer at region $3 \mathrm{p} 21.3$ and found that $B L U, R A S S F 1 A, S E M A 3 B$ and $S E M A 3 F$ play vital roles in the development and progression of NPC or lung cancer (26-30). Similar studies performed in OSCCs revealed that the expression levels of the LTF, LIMDI, CACNA2D2, RASSF1A, CDC25A and SCOTIN genes located at $3 \mathrm{p} 21.3$ were decreased by $67.6,53.2,23.7,15.1,5.3$ and $0.58 \%$, respectively. LOH and DNA methylation alterations may account for the abnormal expression of LTF, LIMDI, CACNA2D2 and RASSF1A.

In the present study, based on the above-mentioned research, bioinformatics analysis was carried out to screen candidate TSGs located at 3p21.3, which to date have not been or have been inadequately studied in OSCC. The methylation state in the promoters of TSGs was also analyzed using methylation-specific PCR (MSP) to explore the role of DNA methylation in the downregulation of TSGs in OSCCs.

\section{Materials and methods}

Selecting target genes located at 3p21.3. On the basis of a database search (PubMed, Gene Card, OMIM and Gene Map), using '3p21.3' and 'tumor-suppressor genes' as search terms, 10 genes were selected for analysis based on the following inclusion criteria: i) they were previously reported to exhibit low expression or no expression in other tumor types; and ii) the functions of these genes were not previously studied or inadequately studied in OSCCs.

Cell line and tissues. TCA8113, a tongue cancer cell line, was provided by the Cancer Research Institute of Central South University. TCA8113 cells were cultured in RPMI-1640 supplemented with $10 \%$ fetal calf serum at $37^{\circ} \mathrm{C}$ in a humidified atmosphere with $5 \% \mathrm{CO}_{2}$. Thirty-six pairs of normal and tumor tissues from OSCC patients were obtained from the Hunan Cancer Hospital (Changsha, Hunan, China) and the Second Xiangya Hospital of Central South University (Changsha, Hunan, China) with informed patient consent prior to treatment. All fresh tissues were snap-frozen in liquid nitrogen and stored until required. Clinicopathological information of the patients is presented in Table I.

DNA and RNA extraction. gDNA from all specimens as well as from $1 \times 10^{6}$ cells was extracted using an improved method for extracting high-molecular-weight DNA with phenol/chlo- roform according to previously reported procedures (31). Total RNA was isolated from a $100 \mathrm{mg}$ sample from each specimen and a total number of $10^{7}$ cells using TRIzol reagent according to the manufacturer's protocol (Invitrogen, USA).

Reverse transcription-PCR (RT-PCR). Total RNA was treated with DNAse I (Roche Diagnostics, USA) and purified in accordance with the manufacturer's instructions. Reverse transcription was performed with $1 \mu \mathrm{g}$ of treated total RNA using AMV reverse transcriptase (Promega, Madison, WI, USA). An equal amount of cDNA from each sample was amplified using specific primers for each gene (Table II). The conditions for PCR reactions were as follows: $95^{\circ} \mathrm{C}$ for $5 \mathrm{~min}$, followed by $30-34$ cycles of $94^{\circ} \mathrm{C}$ for $35 \mathrm{sec}, 55-58^{\circ} \mathrm{C}$ for $35 \mathrm{sec}, 72^{\circ} \mathrm{C}$ for $35 \mathrm{sec}$, and $72^{\circ} \mathrm{C}$ for $10 \mathrm{~min}$ for the extension. The PCR products were electrophoresed on $1 \%$ agarose gel and visualized by ethidium bromide staining.

Gray scale scanning and data analysis. The intensity of each electrophoretic band was measured using ImageMaster VDS (Pharmacia Biotech Inc., Piscataway, NJ), and analyzed by VDS software version 3.0 for band quantification with $G A P D H$ as an internal control. The expression levels of target genes in the tumors and normal tissues were investigated after they were normalized by transforming them into two groups according to the ratios of the band intensity of the target genes over that of GAPDH for the same sample as previously described (32). A ratio $>2$ indicated that the corresponding gene was upregulated in OSCC and a ratio $<1 / 2$ indicated that the corresponding gene was downregulated in OSCC and all other ratio values indicated that the corresponding genes were expressed at a normal level. Each RT-PCR reaction was carried out in triplicate.

Methylation-specific PCR (MSP). MSP was performed to analyze the methylation state in the promoter regions of the target genes both in OSCC tissues and TCA8113 cells. One microgram gDNA from OSCC tissues and TCA8113 cells was treated with bisulfite, similar to previous methods $(33,34)$. Each sample was amplified with two sets of primers, one set for methylated DNA and one set for unmethylated DNA. When gDNA was treated with bisulphite, the unmethylated cytosine was tranformed to uracil while methylated cytosine was unaffected. Thus, the methylated and unmethylated promoters were distinguished by MSP. The primers used for the methylated and unmethylated target gene promoter regions are listed in 
Table II. Summary of primer sequences, annealing temperatures and product sizes.

\begin{tabular}{|c|c|c|c|c|c|}
\hline & Squence $\left(5^{\prime}-3^{\prime}\right)$ & $\begin{array}{l}\text { Product size } \\
\quad(\mathrm{bp})\end{array}$ & $\begin{array}{l}\text { Annealing } \\
\text { temperature }\left({ }^{\circ} \mathrm{C}\right)\end{array}$ & Cycles & Ref. \\
\hline \multicolumn{6}{|c|}{ Primer for RT-PCR } \\
\hline$G A P D H$ & $\begin{array}{l}\text { F: GAGATCCCTCCAAAATCAAGTG } \\
\text { R: GAGTCCTTCCACGATACCAAAG }\end{array}$ & 282 & 58 & 28 & \\
\hline$A X U D 1$ & $\begin{array}{l}\text { F: TGCGTAACAGTCTCCCACTG } \\
\text { R: CCTGATTTCAGCCCTGTCTC }\end{array}$ & 301 & 58 & 30 & \\
\hline$B A P 1$ & $\begin{array}{l}\text { F: TACGCTACAACCGTGCTGTC } \\
\text { R: TCAGCCTCCACACACTTCAG }\end{array}$ & 295 & 58 & 30 & \\
\hline FUS1 & $\begin{array}{l}\text { F: GGATCTGGCTCACGAGTTCT } \\
\text { R: GAAGGTTATGGGCCAACAGA }\end{array}$ & 296 & 55 & 30 & \\
\hline GNAT1 & $\begin{array}{l}\text { F: CATCTGCAACCACCGCTAC } \\
\text { R: CGCACGTCATGTGGGAATA }\end{array}$ & 221 & 62 & 32 & \\
\hline LARS2 & $\begin{array}{l}\text { F: TTACTGGATGCCTGTGGATT } \\
\text { R: CCCGTTGTGTTTGGACTTAC } \\
\text { R: GCCTGCGACATACTGTGGTC }\end{array}$ & 295 & 56 & 30 & \\
\hline NPRL2 & $\begin{array}{l}\text { F: CGCATTGCTATCCAGAACCT } \\
\text { R: CTTCATAAGCCCGAACTGGA }\end{array}$ & 300 & 60 & 30 & \\
\hline RASSF $1 A$ & $\begin{array}{l}\text { F: ACACGTGGTGCGACCTCT } \\
\text { R: GATGAAGCCTGTGTAAGAACCGTCCT }\end{array}$ & 308 & 58 & 32 & \\
\hline SEMA3B & $\begin{array}{l}\text { F: GTCCTCTTCATTGGCACAGAC } \\
\text { R: GTCGCCATTCCTTACGTCTT }\end{array}$ & 345 & 56 & 30 & \\
\hline SEMA3F & $\begin{array}{l}\text { F: AGTGTCCGTACGATCCCAAG } \\
\text { R: ATGACAGGGTTCCTCACGTC }\end{array}$ & 466 & 58 & 32 & \\
\hline ZNF35 & $\begin{array}{l}\text { F: GCGCACATAGGCAGTACTCA } \\
\text { R: TGTCTGAAGACCCTGCACTG }\end{array}$ & 296 & 58 & 30 & \\
\hline \multicolumn{6}{|c|}{ Primer for MSP } \\
\hline GNAT1 & $\begin{array}{l}\text { MF: GTAAAAGATATATTTATGGTCGGC } \\
\text { MR: CCTCCCAAATAACTAAAATTACGAA } \\
\text { UF: AAAAGATATATTTATGGTTGGGTGA } \\
\text { UR: CCTCCCAAATAACTAAAATTACAAA }\end{array}$ & 195 & 59 & & \\
\hline$S E M A 3 B$ & $\begin{array}{l}\text { MF: TGGTTAGGCGGGGTATTTTC } \\
\text { MR: TCAACAATAAAAACGAAAACG } \\
\text { UF: GTGGTTAGGTGGGGTATTTTT } \\
\text { UR: ATCAACAATAAAAACAAAAACA }\end{array}$ & 133 & 54 & & $(52)$ \\
\hline
\end{tabular}

F, forward primer; $\mathrm{R}$, reverse primer; $\mathrm{M}$, methylation; $\mathrm{U}$, unmethylation.

Table II. The PCR products were analyzed by $1 \%$ agarose gel electrophoresis and ethidium bromide staining.

Sequencing. DNA sequencing was carried out to identify the methylated and unmethylated sequences. MSP products were electrophoresed on a $1 \%$ agarose gel, and the products were recovered by using the QIAquick Gel Extraction kit (Qiagen, USA). The purified DNA was then cloned into the pMD18-T (Takara, Japan) vector and transformed into Escherichia coli strain Top 10 according to the manufacturer's instructions.
The recombinant plasmid DNA extracted from the 5 randomly selected positive clones was used for sequencing.

Treatment of TCA8113 cells with 5-aza-2'-deoxycytidine (5-Aza-Cdc). TCA8113 cells were plated in 6-well plates at a density of $1 \times 10^{5}$ cells/well and cultured overnight. On the morning of the next day, the TCA8113 cells were treated with 5-Aza-Cdc, a type of demethylation reagent, at final concentrations (as control) of $01,5,10,50$ and $100 \mu \mathrm{M}$, respectively. After changing the medium and treating cells with 5-Aza-Cdc 


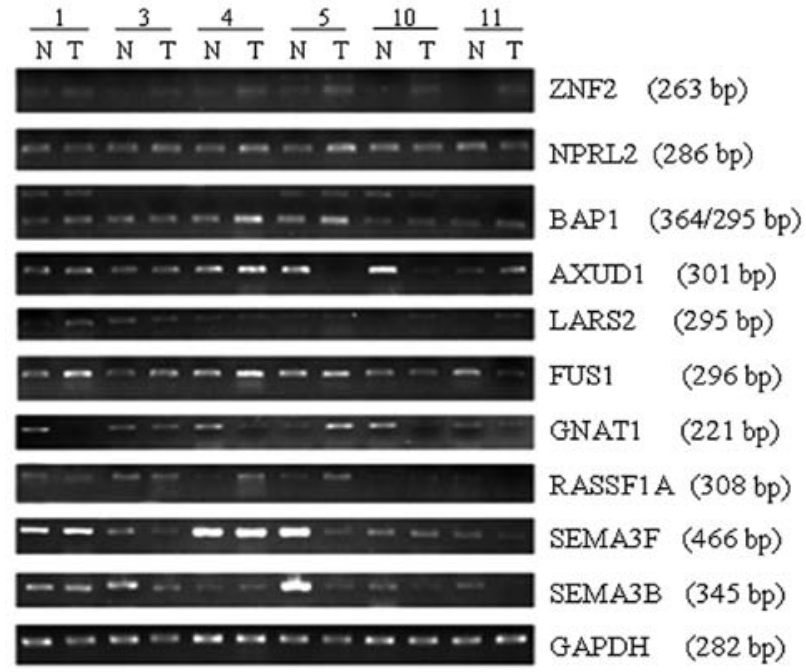

Figure 1. Expression of genes located at region 3p12.3 in OSCC tissues by RT-PCR. N, normal tissues as control; T, OSCC tissues.

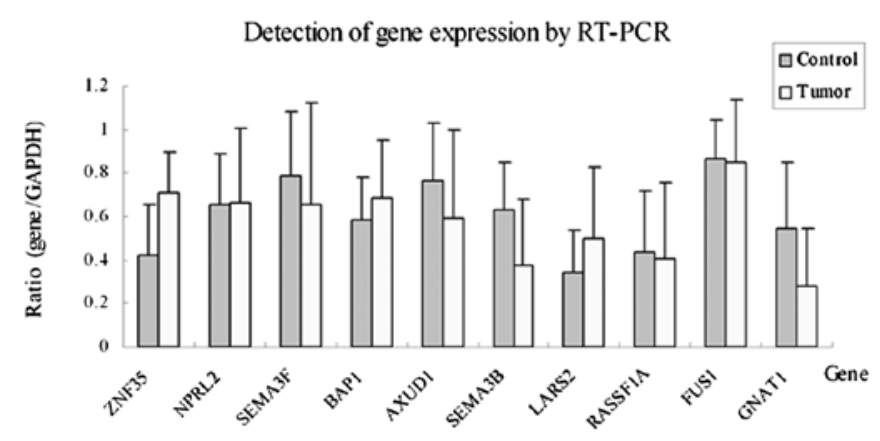

Figure 2. Relative expression of genes located at region $3 \mathrm{p} 12.3$ in OSCC tissues.

once per $24 \mathrm{~h}$ for 4 consecutive days, TCA8113 cells were collected for RNA and DNA extraction to perform RT-PCR and MSP analysis.

Statistical analysis. Statistical analysis was performed using the Chi-square test and the Student's t-test. In all analyses, SPSS 11.5 statistical software (SPSS, Chicago, IL) was used, and a P-value $<0.05$ was considered to indicate a statistically significant result.

\section{Results}

Differential expression of the selected genes in OSCC and normal tissues. We selected 10 genes using ' $3 \mathrm{p} 21.3$ ' and 'tumor-suppressor genes' as the search terms in several databases (PubMed, Gene Card, OMIM and Gene Map). The selected genes are listed in Table II.

Differential expression of the target genes was assessed using semi-quantitative RT-PCR combined with Gray Scale Scanning analysis in 12 pairs of OSCC tissues and contralateral normal tissues. The results revealed that the expression of GNAT1, SEMA3B and AXUD1 was downregulated or deficient in the OSCC tissues with percentages of $58.3(7 / 12), 41.7$ $(5 / 12)$ and $41.7 \%(5 / 12)$, respectively $(\mathrm{P}<0.05)$. The expression
A

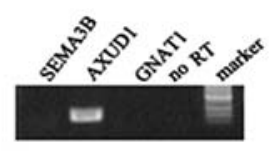

B

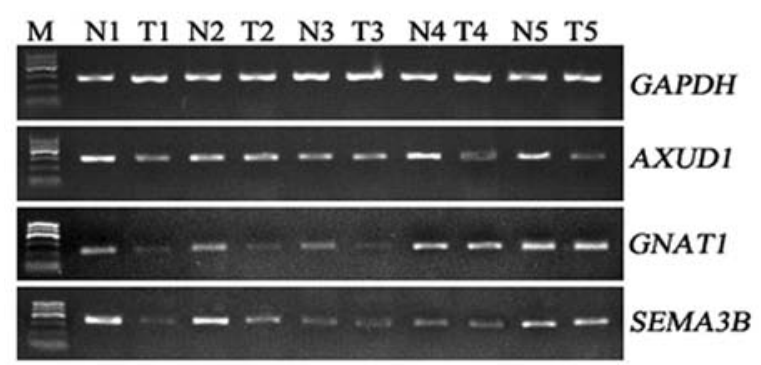

C Detection gene expression by RT-PCR

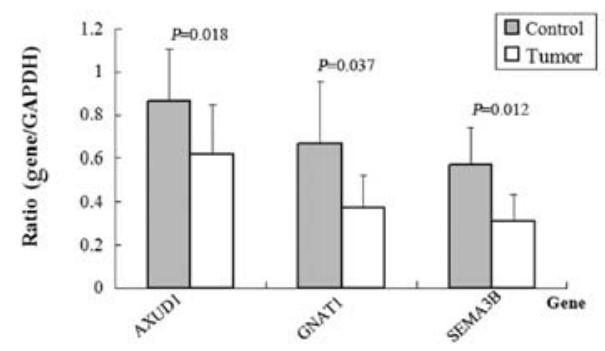

Figure 3. Expression of GNAT1, SEMA3B and AXUD1 in OSCC tissues and the TCA8113 cell line. (A) Expression of GNAT1, SEMA3B and AXUD1 in TCA8113 cells. (B) Verification of the expression of GNAT1, SEMA3B and $A X U D 1$ in additional OSCC tissue samples. (C) Verification of relative expression of GNAT1, SEMA3B and AXUD1 located at region 3p12.3 in additional OSCC tissues.

of ZNF35 was upregulated in $33.3 \%$ (4/12) of OSCC tissues. No significant difference in expression for NPRL2, BAP1, FUS1, LARS2, RASSF1A and SEMA3F was observed between the OSCC and normal tissues ( $\mathrm{P}>0.05)$ (Figs. 1 and 2). We selected three downregulated genes, GNAT1, SEMA3B and $A X U D 1$, for further study.

Expression of GNAT1, SEMA3B and AXUD1 in OSCC tissues and the TCA8113 cell line. RT-PCR was performed to verify the low expression of GNAT1, SEMA3B and AXUD1 in 36 OSCC tissues, corresponding adjacent normal tissues and TCA8113 cells. The results confirmed that the expression of GNAT1, SEMA3B and AXUD1 was downregulated or undetectable in $44.4(16 / 36) 50(18 / 36)$ and $47.2 \%(17 / 36)$ of the OSCC tissues, respectively, compared with the normal expression of these genes in adjacent normal tissues $(\mathrm{P}<0.05)($ Fig. $3 \mathrm{~B}$ and C). No expression of GNAT1 and SEMA3B was detected and $A X U D 1$ was expressed at a normal level in the TCA8113 cells (Fig. 4A) as compared with the expression in OSCC tissues. No significant correlation was observed between the downregulated genes and OSCC metastasis and patient gender when compared with the clinical data (Table III).

Hypermethylation of GNAT1 and SEMA3B in OSCC tissues. We analyzed the methylation status of $\mathrm{CpG}$ islands in the promoter region of GNAT1 and SEMA3B in several 
Table III. Statistical analysis of the correlation between the downregulated genes and tumor metastasis.

\begin{tabular}{|c|c|c|c|c|c|c|c|}
\hline \multirow[b]{3}{*}{ Groups } & \multirow[b]{3}{*}{ Cases } & \multicolumn{6}{|c|}{ Genes } \\
\hline & & \multicolumn{2}{|c|}{$A X U D 1$} & \multicolumn{2}{|c|}{ GNAT1 } & \multicolumn{2}{|c|}{$S E M A 3 B$} \\
\hline & & $\mathrm{N}(\%)$ & $\mathrm{U}(\%)$ & $\mathrm{N}(\%)$ & $\mathrm{U}(\%)$ & $\mathrm{N}(\%)$ & $\mathrm{U}(\%)$ \\
\hline Metastasis & 17 & $10(27.8)$ & $7(19.4)$ & $10(27.8)$ & $7(19.4)$ & $10(27.8)$ & $7(19.4)$ \\
\hline Non-metastasis & 19 & $9(25.0)$ & $10(27.8)$ & $9(25.0)$ & $10(27.8)$ & $8(22.2)$ & $11(30.1)$ \\
\hline$\chi^{2}$ & & \multicolumn{2}{|c|}{0.472} & \multicolumn{2}{|c|}{0.139} & \multicolumn{2}{|c|}{1.003} \\
\hline P-value & & \multicolumn{2}{|c|}{0.492} & \multicolumn{2}{|c|}{0.709} & \multicolumn{2}{|c|}{0.317} \\
\hline
\end{tabular}

$\mathrm{N}$, normal expression; $\mathrm{U}$, underexpression.

A

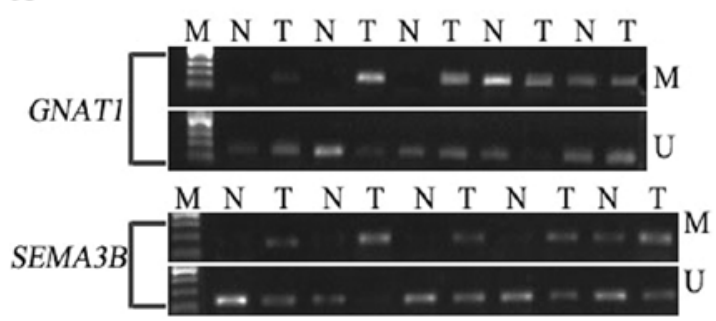

B
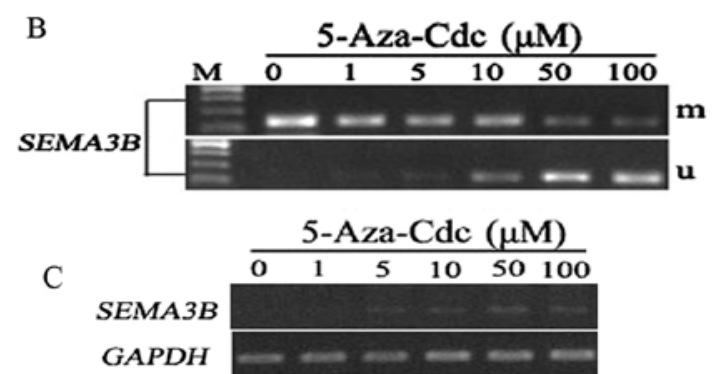

D
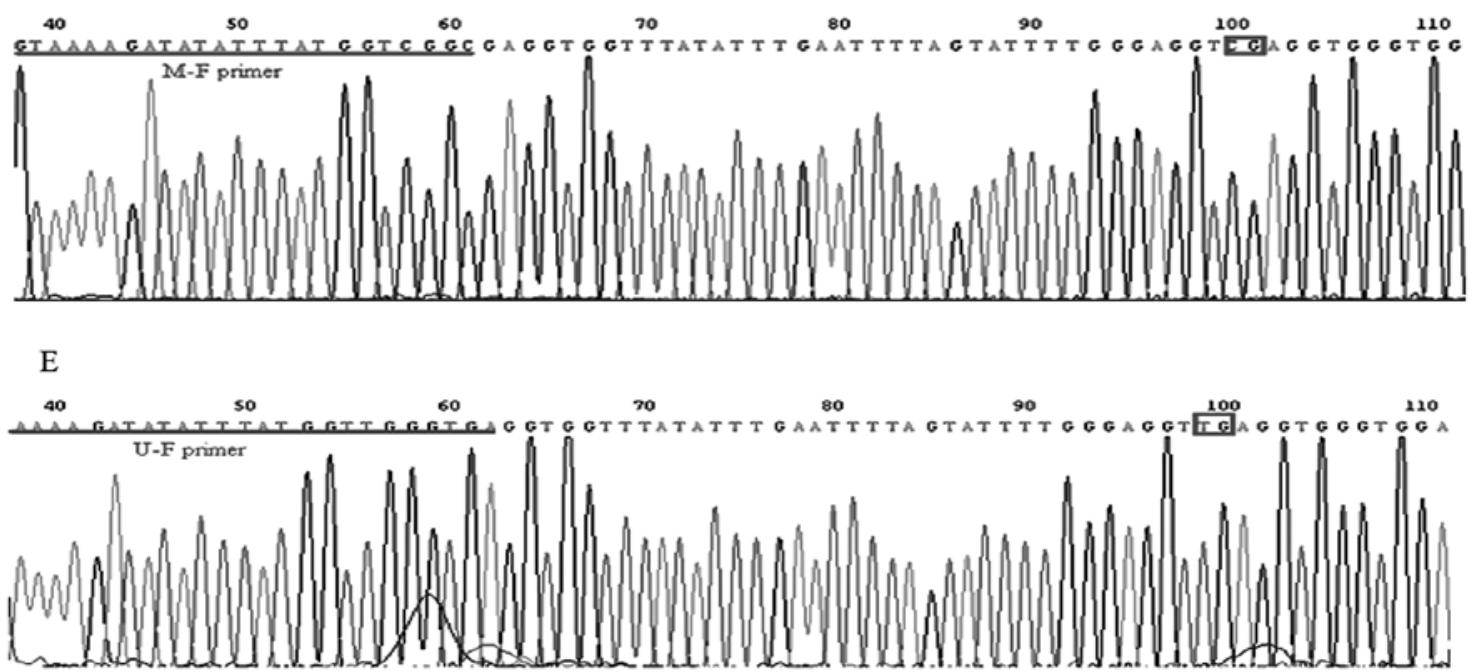

Figure 4. The hypermethylation status of GNAT1 and SEMA3B was detected in OSCC tissues by MSP. 5-Aza-Cdc partially rescued the expression of SEMA3B in TCA8113 cells. (A) Analysis of the methylation of GNAT1 and SEMA3B in OSCC tissues by MSP. N, normal control tissues; T, OSCC tissues; M, methylated; U, unmethylated. (B and C) Expression of SEMA3B in TCA8113 cells treated with different concentrations of 5-Aza-Cdc. m, methylated; u, unmethylated. (D and E) Confirmation of the outcome of MSP by sequencing.

OSSC tissue samples and adjacent non-cancerous tissues. Hypermethylation of GNAT1 and SEMA3B was found in 75 $(12 / 16)$ and $77.8 \%(14 / 18)$ of OSSC tissues, respectively. In the non-cancerous tissues, different levels of methylation were also detected with a percentage of $56.25 \%(9 / 16)$ for GNAT1 and $38.9 \%$ (8/18) for SEMA3B (Fig. 4A). The results were also confirmed by the sequencing of the MSP products (Fig. 4D and E). Statistical analysis indicated that there was a significant difference in the frequency of methylation of $S E M A 3 B$ between the OSCC and non-cancerous tissues ( $\chi^{2}$ test, $\mathrm{P}=0.018$ $<0.05$ ) (Table IV), while no statistical significance was found in the frequency of methylation of GNAT1 between the OSCC and non-cancerous tissues ( $\chi^{2}$ test, $\left.\mathrm{P}=0.709>0.05\right)$, suggesting that methylation of the promoter plays an important role in the downregulation of the SEMA3B gene in OSSC tissues.

5-Aza-Cdc partially recovers the expression of SEMA3B in TCA8113 cells. RNA and DNA were extracted from TCA8113 cells treated with different concentrations of 5-Aza-Cdc for 4 days for expression and methylation analysis of $S E M A 3 B$ by RT-PCR and MSP. The results demonstrated that SEMA3B began to be expressed in the TCA8113 cells when treated 
Table IV. Statistical analysis of the gene promoter methylation status in OSCC tissues.

\begin{tabular}{|c|c|c|c|c|c|c|}
\hline \multirow[b]{3}{*}{ Groups } & \multicolumn{6}{|c|}{ Genes } \\
\hline & \multicolumn{3}{|c|}{ GNATl } & \multicolumn{3}{|c|}{ SEMA3B } \\
\hline & $\mathrm{n}$ & $\mathrm{M}(\%)$ & $\mathrm{U}(\%)$ & $\mathrm{n}$ & M (\%) & $\mathrm{U}(\%)$ \\
\hline Control & 16 & $9(56.25)$ & 7 (43.75) & 18 & $7(38.9)$ & $11(61.1)$ \\
\hline Tumor & 16 & $12(75.0)$ & $4(25.0)$ & 18 & $14(77.8)$ & $4(22.2)$ \\
\hline$\chi^{2}$ & \multicolumn{3}{|c|}{1.247} & \multicolumn{3}{|c|}{5.60} \\
\hline P-value & \multicolumn{3}{|c|}{0.264} & \multicolumn{3}{|c|}{0.018} \\
\hline
\end{tabular}

Tumor, OSCC tissues; Control, non-cancerous tissues; M, methylated product; $\mathrm{U}$, unmethylated product.

with a concentration of 5-Aza-Cdc at $5 \mu \mathrm{M}$ (Fig. 4C). More unmethylated products were amplified from the DNA samples of TCA8113 cells when the higher concentration of 5-Aza-Cdc was administered (Fig. 4B). This suggests that methylation of the promoter plays a critical role in the downregulation of this gene in TCA8113 cells.

\section{Discussion}

Inactivation of TSGs and overexpression of oncogenes are the main causes for tumorigenesis. LOH and hypermethylation in promoter regions are the common reasons accounting for the inactivation of TSGs. The short arm of human chromosome 3 , a region with a high frequency of $\mathrm{LOH}$, is considered to be rich in TSG-containing sites as indicated by previous studies on lung cancer, breast cancer, ovarian cancer and other malignant tumors (35). Screening tumor-related TSG candidates is an available method based on loss of a chromosome region. Numerous candidate TSGs have been identified in high frequency chromosome-deleted regions such as $D L C-1$, a potential TSG at $8 \mathrm{p} 21$, a region frequently deleted in various types of cancers $(33,36)$ and DMRT1, DMRT3 and DOCK8 located at $9 \mathrm{p} 24.3$, a deleted region in squamous cell lung carcinoma (37). In this study, we selected 10 genes including AXUD1, BAP1, FUS1, GNAT1, LARS2, NPRL2, RASSF1A, $S E M A 3 F, S E M A 3 B$ and ZNF35 which were located on region 3 p21.3 and analyzed the expression of these genes using RT-PCR to find candidate TSGs in OSCC. Three downregulated genes, $S E M A 3 B, A X U D 1$ and $G N A T 1$, were identified and both SEMA3B and GNAT1 were downregulated in TCA8113 cells.

$A X U D 1$, also termed cysteine-serine-rich nuclear protein 1 gene (CSRNPI), was cloned by Ishiguro et al (38) while studying the functions of AXIN1 which encodes one of the apoptotic proteins induced by TGF- $\beta$ in hepatoma carcinoma cells. The full length AXUD1 cDNA is $3188 \mathrm{bp}$ and encodes a $64-\mathrm{kDa}$ protein containing 596 amino acids and is located mainly in the nucleus. AXUD1, a downstream responsive protein for AXIN1, negatively regulates the Wnt pathway which plays an important role in early embryonic development. Studies have shown that the abnormal regulation of the Wnt pathway is related to tumorigenesis. The expression of $A X U D 1$, which is high in normal tissues such as lung, placenta, skeletal muscle, pancreas and leukocytes, was found to be downregulated in lung cancer hepatoma and colorectal carcinoma, suggesting that AXUD1 may be a candidate TSG (38). Simultaneously, knockdown of the expression of DAXUD1, a orthologue of the AXUD1/CSRNP family in Drosophila, was found to induce imaginal cells to proliferate. Conversely, overexpression of $D A X U D 1$ retarded cell cycle progression at mitosis behaving similar to a TSG (39). Our study showed that the expression of AXUDl was downregualted in $47.2 \%$ (17/36) of the OSCC tissues. However, this downregulation had no correlation with patient gender and tumor metastasis, indicating that $A X U D 1$ may be involed in the early malignant transformation of the oral mucous membrane. The function of this gene in OSCC warrants further study.

Guanine nucleotide-binding protein $\mathrm{G}$ ( $\mathrm{G}$ protein) subunit $\alpha-1$ a encoded by GNAT1 is an intracellular protein involved in light signal transduction in the retina (40). G protein, as an energy regulator, participates in the regulation of different transmembrane signal transduction pathways (40). Yi et al (41) found that expression of GNAT1 was downregulated in $72.7 \%$ (24/33) of nasopharyngeal carcinoma tissues, which was markedly lower than that in chronic nasopharyngitis tissues $(100 \%, 15 / 15)$. The study also demonstrated that downregulation of GNATI was associated with $\mathrm{LOH}$, but not with abnormal methylation of the promoter region. In our study, in comparison with the expression in normal control tissues, the expression of GNATl was significantly downregulated in $44.4 \%$ of the OSCC tissues $(\mathrm{P}=0.037<0.05)$ and in TCA8113 cells. However, the downregulation of GNATI had no correlation with patient gender and tumor metastasis, suggesting that GNAT1 may be involved in the early development of OSCC.

$S E M A 3 B$, a member of the human semaphoring family is involved in apoptosis $(42,43)$ and in antitumor pathways regulated by p53 (44). SEMA3B was cloned by Sekido et al (45). SEMA3B cDNA encodes an $83-\mathrm{kDa}$ protein of 749 amino acids. Using Northern blot analysis, Lerman and Minna (46) detected wide expression of a 3.4-kb SEMA3B transcript that was strongest in placenta, weaker in other tissues including lung and testis and not detectable in small-cell lung cancer cell lines. Missense mutations were found in non-small cell lung cancer cell lines. The authors also showed that SEMA3B is likely to be an extracellular secreted protein. Lerman and Minna concluded that $S E M A 3 B$ is an attractive candidate tumor-suppressor gene for methylation and functional analysis. In the present study, we detected the expression of $S E M A 3 B$ mRNA in OSCC tissues and adjacent control tissues. The results showed that the expression level of $S E M A 3 B$ was significantly lower in OSCC tissues than that in control tissues, which was confirmed by undetectable expression of $S E M A 3 B$ in TCA8113 cells. The $\chi^{2}$ test confirmed that no significant correlation existed between the downregulated expression of $S E M A 3 B$ and patient gender and tumor metastasis.

DNA hypermethylation, one of the most common epigenetic alterations, is involved in inactivation of the expression of many TSGs (47-49). MSP is a technique that has facilitated the detection of promoter hypermethylation at $\mathrm{CpG}$ islands in cell lines and clinical samples, including fresh and frozen tissues (50). Riquelme et al (51) found that the methylation ratio of the promoter region of $S E M A 3 B$ is $92 \%(46 / 50)$ in 
gallbladder carcinoma, suggesting that the methylation of SEMA3B may participate in the carcinogenesis and progression of gallbladder carcinoma. The hypermethylation status of $S E M A 3 B$ was also recorded in non-small cell lung cancer decreasing the expression of $\operatorname{SEMA3B}(52,53)$ and in nasopharyngeal carcinoma for GNAT1, however, it did not account for the low expression of GNAT1 (41).

Thus, MSP was performed with DNA samples from OSCC tissues, control tissues and 5-Aza-Cdc-treated TCA8113 cells. Hypermethylation status of $S E M A 3 B$ in promoter regions was assessed in OSCC tissues, and the expression of $S E M A 3 B$ was partly recovered in TCA8113 cells treated with 5-Aza$\mathrm{Cdc}$, demonstrating that the hypermethylation status in the promoter region led to, at least partially, low expression of SEMA3B in OSCC in accordance with studies in other cancer types (51-53). As for GNAT1, although hypermethylation in the promoter regions was observed in OSSC tissues, there was no significant difference in expression between OSSC tissues and control samples. Futher studies should be conducted to explore the reasons for the low expression of GNAT1.

In conclusion, our study demonstrated that $A X U D 1$, GNAT1 and $S E M A 3 B$, three candidate TSGs located at 3p21.3, may be involved in the development of OSCC, and methylation in the promoter region plays a critical role in the low expression of $S E M A 3 B$. These findings may lead to new avenues for the early diagnosis and therapy of OSCC.

\section{References}

1. Massano J, Regateiro FS, Januario G and Ferreira A: Ora squamous cell carcinoma: review of prognostic and predictive factors. Oral Surg Oral Med Oral Pathol Oral Radiol Endod 102 67-76, 2006.

2. Parkin DM, Bray F, Ferlay J and Pisani P: Global cancer statistics, 2002. CA Cancer J Clin 55: 74-108, 2005.

3. Lippman SM and Hong WK: Molecular markers of the risk of oral cancer. N Engl J Med 344: 1323-1326, 2001.

4. Vokes EE, Weichselbaum RR, Lippman SM and Hong WK: Head and neck cancer. N Engl J Med 328: 184-194, 1993.

5. Zhou W, Feng X, Li H, et al: Inactivation of LARS2, located at the commonly deleted region $3 \mathrm{p} 21.3$, by both epigenetic and genetic mechanisms in nasopharyngeal carcinoma. Acta Biochim Biophys Sin 41: 54-62, 2009.

6. Friend SH, Bernards R, Rogelj S, et al: A human DNA segment with properties of the gene that predisposes to retinoblastoma and osteosarcoma. Nature 323: 643-646, 1986.

7. Chiba I, Shindoh M, Yasuda M, et al: Mutations in the p53 gene and human papillomavirus infection as significant prognostic factors in squamous cell carcinomas of the oral cavity. Oncogene 12: 1663-1668, 1996.

8. Call KM, Glaser T, Ito CY, et al: Isolation and characterization of a zinc finger polypeptide gene at the human chromosome 11 Wilms' tumor locus. Cell 60: 509-520, 1990.

9. Kamb A, Shattuck-Eidens D, Eeles R, et al: Analysis of the p16 gene (CDKN2) as a candidate for the chromosome 9p melanoma susceptibility locus. Nat Genet 8: 23-26, 1994.

10. Aoki $\mathrm{K}$ and Taketo MM: Adenomatous polyposis coli (APC): a multi-functional tumor suppressor gene. J Cell Sci 120: 3327-3335, 2007.

11. Hahn SA, Schutte M, Hoque AT, et al: DPC4, a candidate tumor suppressor gene at human chromosome 18q21.1. Science 271: 350-353, 1996.

12. Ohta M, Inoue H, Cotticelli MG, et al: The FHIT gene, spanning the chromosome 3p14.2 fragile site and renal carcinoma-associated $\mathrm{t}(3 ; 8)$ breakpoint, is abnormal in digestive tract cancers. Cell 84: 587-597, 1996.

13. Li J, Yen C, Liaw D, et al: PTEN, a putative protein tyrosine phosphatase gene mutated in human brain, breast, and prostate cancer. Science 275: 1943-1947, 1997.
14. Steck PA, Pershouse MA, Jasser SA, et al: Identification of a candidate tumour suppressor gene, MMAC1, at chromosome $10 \mathrm{q} 23.3$ that is mutated in multiple advanced cancers. Nat Genet 15: 356-362, 1997.

15. Imai FL, Uzawa K, Miyakawa A, Shiiba M and Tanzawa H: A detailed deletion map of chromosome 20 in human oral squamous cell carcinoma. Int J Mol Med 7: 43-47, 2001

16. Miyakawa A, Wang XL, Nakanishi H, et al: Allelic loss on chromosome 22 in oral cancer: Possibility of the existence of a tumor suppressor gene on 22q13. Int J Oncol 13: 705-709, 1998.

17. Sparano A, Quesnelle KM, Kumar MS, et al: Genome-wide profiling of oral squamous cell carcinoma by array-based comparative genomic hybridization. Laryngoscope 116: 735-741, 2006.

18. Yamamoto N, Mizoe J, Numasawa H, Tsujii H, Shibahara T and Noma H: Allelic loss on chromosomes 2q, 3p and 21q: possibly a poor prognostic factor in oral squamous cell carcinoma. Oral Oncol 39: 796-805, 2003.

19. Roz L, Wu CL, Porter S, et al: Allelic imbalance on chromosome $3 \mathrm{p}$ in oral dysplastic lesions: an early event in oral carcinogenesis. Cancer Res 56: 1228-1231, 1996.

20. Yamamoto N, Kuroiwa T, Katakura A, Shibahara T and Choudhury C: Loss of heterozygosity (LOH) on chromosomes $2 q, 3 p$ and $21 q$ in Indian oral squamous cell carcinoma. Bull Tokyo Dent Coll 48: 109-117, 2007.

21. van den Berg A, Dijkhuizen T, Draaijers TG, et al: Analysis of multiple renal cell adenomas and carcinomas suggests allelic loss at 3 p21 to be a prerequisite for malignant development. Genes Chromosomes Cancer 19: 228-232, 1997.

22. Hung J, Kishimoto Y, Sugio K, et al: Allele-specific chromosome $3 p$ deletions occur at an early stage in the pathogenesis of lung carcinoma. JAMA 273: 1908, 1995.

23. Zhu Y, Spitz MR, Zheng YL, Hong WK and Wu X: BPDEinduced lymphocytic 3 p21.3 aberrations may predict head and neck carcinoma risk. Cancer 95: 563-568, 2002.

24. Senchenko V, Liu J, Braga E, et al: Deletion mapping using quantitative real-time PCR identifies two distinct $3 \mathrm{p} 21.3$ regions affected in most cervical carcinomas. Oncogene 22: 2984-2992, 2003.

25. Senchenko VN, Liu J, Loginov W, et al: Discovery of frequent homozygous deletions in chromosome 3p21.3 LUCA and AP20 regions in renal, lung and breast carcinomas. Oncogene 23: $5719-5728,2004$.

26. Baylin SB, Esteller M, Rountree MR, Bachman KE, Schuebel K and Herman JG: Aberrant patterns of DNA methylation, chromatin formation and gene expression in cancer. Hum Mol Genet 10: 687-692, 2001.

27. Bird A: DNA methylation patterns and epigenetic memory. Genes Dev 16: 6-21, 2002.

28. Bird AP: CpG-rich islands and the function of DNA methylation. Nature 321: 209-213, 1986.

29. Merlo A, Herman JG, Mao L, et al: $5^{\prime}$ CpG island methylation is associated with transcriptional silencing of the tumour suppressor p16/CDKN2/MTS1 in human cancers. Nat Med 1: 686-692, 1995.

30. Steinmann K, Sandner A, Schagdarsurengin $U$ and Dammann RH: Frequent promoter hypermethylation of tumorrelated genes in head and neck squamous cell carcinoma. Oncol Rep 22: 1519-1526, 2009.

31. Zhang H, Feng X, Liu W, et al: Underlying mechanisms for LTF inactivation and its functional analysis in nasopharyngeal carcinoma cell lines. J Cell Biochem 112: 1832-1843, 2011.

32. Zhou W, Feng X, Li H, et al: Functional evidence for a nasopharyngeal carcinoma-related gene BCAT1 located at 12p12. Oncol Res 16: 405-413, 2007.

33. Peng D, Ren CP, Yi HM, et al: Genetic and epigenetic alterations of DLC-1, a candidate tumor suppressor gene, in nasopharyngeal carcinoma. Acta Biochim Biophys Sin 38: 349-355, 2006.

34. Zhou L, Feng X, Shan W, et al: Epigenetic and genetic alterations of the EDNRB gene in nasopharyngeal carcinoma. Oncology 72: 357-363, 2007.

35. Tuhkanen H, Anttila M, Kosma VM, et al: Genetic alterations in the peritumoral stromal cells of malignant and borderline epithelial ovarian tumors as indicated by allelic imbalance on chromosome 3p. Int J Cancer 109: 247-252, 2004.

36. Liao YC and Lo SH: Deleted in liver cancer-1 (DLC-1): a tumor suppressor not just for liver. Int J Biochem Cell Biol 40: 843-847, 2008. 
37. Kang JU, Koo SH, Kwon KC and Park JW: Frequent silence of chromosome 9p, homozygous DOCK8, DMRT1 and DMRT3 deletion at 9p24.3 in squamous cell carcinoma of the lung. Int $\mathrm{J}$ Oncol 37: 327-335, 2010.

38. Ishiguro H, Tsunoda T, Tanaka T, Fujii Y, Nakamura $Y$ and Furukawa Y: Identification of AXUD1, a novel human gene induced by AXIN1 and its reduced expression in human carcinomas of the lung, liver, colon and kidney. Oncogene 20 5062-5066, 2001.

39. Glavic A, Molnar C, Cotoras D and de Celis JF: Drosophila Axud1 is involved in the control of proliferation and displays pro-apoptotic activity. Mech Dev 126: 184-197, 2009.

40. Ngo JT, Bateman JB, Klisak I, Mohandas T, Van Dop C and Sparkes RS: Regional mapping of a human rod alpha-transducin (GNAT1) gene to chromosome 3p22. Genomics 18: 724-725, 1993.

41. Yi HM, Ren CP, Peng D, Zhou L, Li H and Yao KT: Expression, loss of heterozygosity, and methylation of GNAT1 gene in nasopharyngeal carcinoma. Ai Zheng 26: 9-14, 2007 (In Chinese).

42. Tomizawa Y, Sekido Y, Kondo M, et al: Inhibition of lung cancer cell growth and induction of apoptosis after reexpression of 3 p21.3 candidate tumor suppressor gene SEMA3B. Proc Natl Acad Sci USA 98: 13954-13959, 2001.

43. Tse C, Xiang RH, Bracht T and Naylor SL: Human semaphorin 3B (SEMA3B) located at chromosome 3p21.3 suppresses tumor formation in an adenocarcinoma cell line. Cancer Res 62: 542-546, 2002.

44. Ochi K, Mori T, Toyama Y, Nakamura Y and Arakawa H: Identification of semaphorin3B as a direct target of p53. Neoplasia 4: 82-87, 2002.

45. Sekido Y, Bader S, Latif F, et al: Human semaphorins A(V) and IV reside in the 3 p21.3 small cell lung cancer deletion region and demonstrate distinct expression patterns. Proc Natl Acad Sci USA 93: 4120-4125, 1996.
46. Lerman MI and Minna JD: The 630-kb lung cancer homozygous deletion region on human chromosome 3 p21.3: identification and evaluation of the resident candidate tumor suppressor genes. The International Lung Cancer Chromosome 3p21.3 Tumor Suppressor Gene Consortium. Cancer Res 60: 6116-6133, 2000.

47. Li W, Li X, Wang W, et al: NOR1 is an HSF1- and NRF1regulated putative tumor suppressor inactivated by promoter hypermethylation in nasopharyngeal carcinoma. Carcinogenesis 32: 1305-1314, 2011.

48. Mao WM, Li P, Zheng QQ, et al: Hypermethylation-modulated downregulation of RASSF1A expression is associated with the progression of esophageal cancer. Arch Med Res 42: 182-188, 2011.

49. Liu WB, Ao L, Zhou ZY, et al: CpG island hypermethylation of multiple tumor suppressor genes associated with loss of their protein expression during rat lung carcinogenesis induced by 3-methylcholanthrene and diethylnitrosamine. Biochem Biophys Res Commun 402: 507-514, 2010.

50. An JH, Choi A, Shin KJ, Yang WI and Lee HY: DNA methylation-specific multiplex assays for body fluid identification. Int $\mathbf{J}$ Legal Med 402: 507-514, 2012.

51. Riquelme E, Tang M, Baez S, et al: Frequent epigenetic inactivation of chromosome $3 \mathrm{p}$ candidate tumor suppressor genes in gallbladder carcinoma. Cancer Lett 250: 100-106, 2007.

52. Kuroki T, Trapasso F, Yendamuri S, et al: Allelic loss on chromosome 3p21.3 and promoter hypermethylation of semaphorin 3B in non-small cell lung cancer. Cancer Res 63: 3352-3355, 2003.

53. Ito M, Ito G, Kondo M, et al: Frequent inactivation of RASSF1A, BLU, and SEMA3B on 3p21.3 by promoter hypermethylation and allele loss in non-small cell lung cancer. Cancer Lett 225: 131-139, 2005. 